\title{
Local genetic and environmental factors in asthma disease pathogenesis: chronicity and persistence mechanisms
}

\author{
S.T. Holgate*, D.E. Davies*, R.M. Powell*, P.H. Howarth*, \\ H.M. Haitchi ${ }^{\#}$ and J.W. Holloway
}

ABSTRACT: While asthma is an inflammatory disorder of the airways usually associated with atopy, an important additional component is involvement of the epithelium and underlying mesenchyme acting as a trophic unit (EMTU).

In addition to allergens, a wide range of environmental factors interact with the EMTU, such as virus infections, environmental tobacco smoke and pollutants, to initiate tissue damage and aberrant repair responses that are translated into remodelling of the airways. While candidate gene association studies have revealed polymorphic variants that influence asthmatic inflammation, positional cloning of previously unknown genes is identifying a high proportion of novel genes in the EMTU.

Dipeptidyl peptidase (DPP) 10 and disintegrin and metalloproteinase (ADAM)33 are newly identified genes strongly associated with asthma that are preferentially expressed in the airway epithelium and underlying mesenchyme, respectively.

Also of increasing importance is the recognition that genes associated with asthma and atopy have important interactions with the environment through epigenetic mechanisms that influence their expression. This type of research will not only identify biomarkers of different types of asthma across the full range of phenotypic expression, but will also identify novel therapeutic targets that could influence the natural history of the heterogenes lung disease.

KEYWORDS: Asthma, environment, genetics, inflammation, remodelling, risk factors

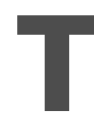

he starting points of the present article are the high and increasing prevalence of asthma in children and adults, its strong genetic and environmental basis, and disease heterogeneity linked to widely different outcomes $[1,2]$. While recent asthma guidelines emphasise the importance of treating the underlying inflammatory response of asthma [3, 4], it is disappointing that beyond corticosteroids and $\beta_{2^{-}}$ adrenoceptor agonists, there has been little new to add to the therapeutic armamentarium (table 1). An important reason for this is that the underlying paradigm for the cellular and mediator pathways that are thought to be involved in asthma fall short of those responsible for its underlying cause [5]. Rather, they are more directed towards the mechanisms of atopy and underlying allergy and not to why the atopic phenotype expresses itself in the lower airways and persists there in association with structural changes. Additional causes for lack of success are: 1) lack of new therapeutic targets; 2) inappropriate or inadequate animal models of chronic disease; 3) lack of access to human diseased tissue and biological fluids; and 4) domination of the current drug market by a few large companies.

Previous articles in this series: No 1: Le Souëf PN, Candelaria P, Goldblatt J. Evolution and respiratory genetics. Eur Respir J 2006; 28: 1258-1263. No. 2: Martinez FD. Genes, environments, development and asthma: a reappraisal. Eur Respir J 2007; 29: 179-184. No. 3: Shapiro SD. Transgenic and gene-targeted mice as models for chronic obstructive pulmonary disease. Eur Respir J 2007; 29: 375-378.

AFFILIATIONS

*Allergy and Inflammation Research, Division of Infection, Inflammation and Repair,

\# IIR Division and

"Division of Human Genetics, School of Medicine, Southampton General Hospital, Southampton, UK.

CORRESPONDENCE

S.T. Holgate

Allergy and Inflammation Research MP810

Level D

Centre Block

Southampton General Hospital

Southampton S016 6YD

UK

Fax: 442380796960

E-mail: sth@soton.ac.uk

Received:

July 032006

Accepted after revision:

October 252006

STATEMENT OF INTEREST

None declared. 


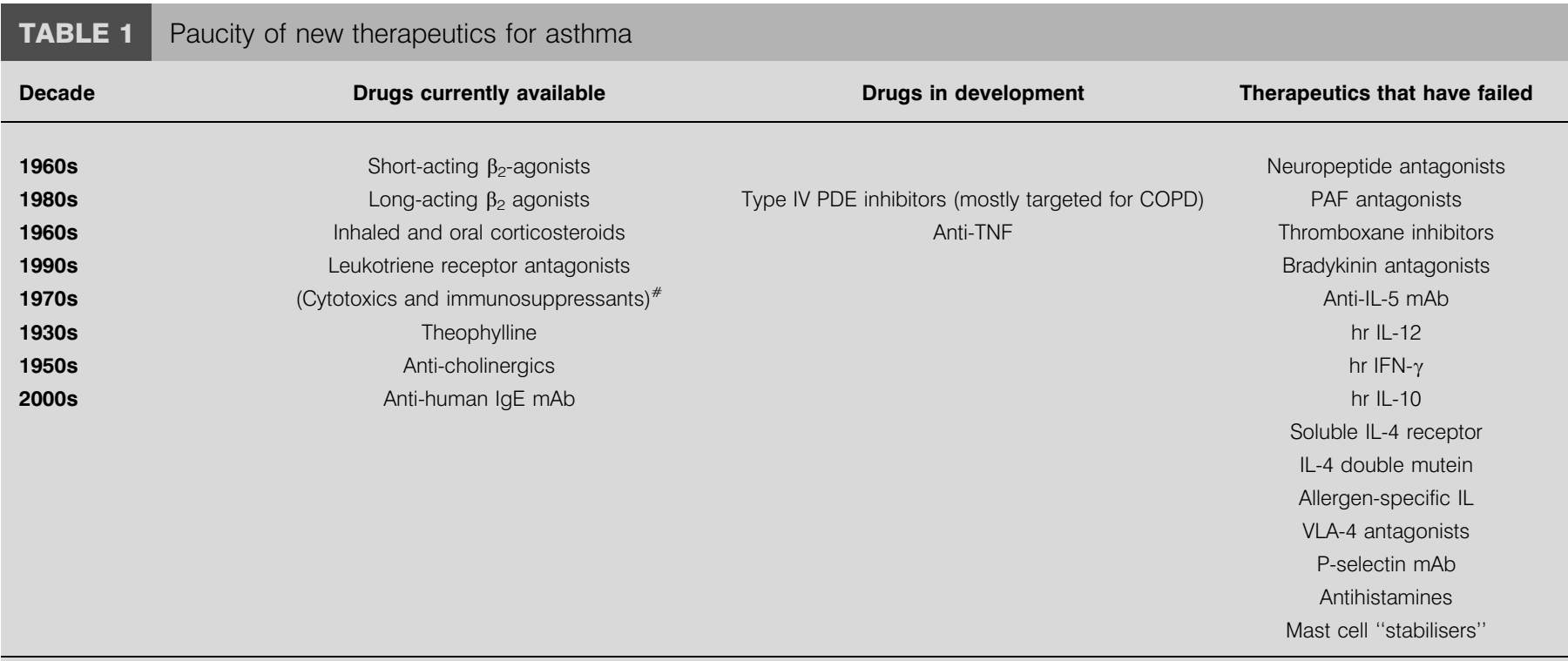

Ig: immunoglobulin; mAb: monoclonal antibody; PDE: phosphodiesterase; COPD: chronic obstructive pulmonary disease; TNF: tumour necrosis factor; PAF: plateletactivating factor; IL: interleukin; hr: human recombinant; IFN: interferon; VLA: very late antigen. ${ }^{*}$ : Rarely used and uncertain efficacy.

\section{ATOPY OR ASTHMA?}

It has long been known that atopy is one of the most important risk factors for asthma but epidemiological studies have revealed that for the disease to develop, additional factors are important [6]. Indeed, in adults and children, atopy [7] or allergen exposure [8] account for substantially $<40 \%$ of the population attributable risk for asthma in children or adults. Environmental factors that have been linked to the rising trends of diseases associated with allergy (including asthma) embrace the concept of an alteration in innate immunity, whereby a change in bacterial flora in the gastrointestinal tract and/or inhalation exposure to bacterial products or respiratory viruses results in an altered trajectory away from the "allergic" T-helper cell (Th)2 pattern towards a more "protective" Th1 or regulatory T-lymphocyte (Tr) pattern $[9,10]$. However, from a large number of studies conducted worldwide, it is now becoming clear that the hygiene hypothesis best fits the causation of atopy rather than that of asthma [9, 11]. Thus, while Th2-mediated inflammation is undoubtedly important in asthma pathogenesis, alone it is insufficient for the disease to be expressed. Morphometry has revealed that thickened asthmatic airways account for a large proportion of bronchial hyperresponsiveness (BHR) and excessive airway narrowing characteristic of chronic disease [12]. In all but the mildest asthma, these structural changes along with BHR are poorly responsive to corticosteroids and, in a susceptible subpopulation with more severe disease, provide an explanation for the accelerated decline in lung function that has been shown to occur over time [13].

\section{EPITHELIAL MESENCHYMAL COMMUNICATION}

Recognising that structural changes, including epithelial mucus metaplasia, deposition of matrix proteins and an increase in smooth muscle and microvessels, are fundamental to the chronicity of asthma, the present authors suggest an alternative paradigm. It is proposed that the high prevalence and rising trends in disease are due to the changes in the environment that have uncovered a pre-existing susceptibility involving locally operating (i.e. tissue-specific) factors [14, 15], as is becoming apparent for other chronic immune-related disorders, such as ulcerative colitis [16] and multiple sclerosis [17]. For asthma, activation of tissue-specific susceptibility genes provides a basis for explaining environmental factors that are more closely associated with asthma (as opposed to atopy), such as exposure to environmental tobacco smoke (ETS) and other air pollutants, a diet low in antioxidants (e.g. vitamin E) and high in fat and proteins, pre- and peri-natal exposure to powerful oxidant stimuli (e.g. paracetamol) and specific respiratory virus infections [9]. It is proposed that in genetically susceptible individuals, exposure to these (and possibly as yet unrecognised) environmental factors results in continued or reactivation of the airways epithelial mesenchymal trophic unit (EMTU) that is intimately involved in branching morphogenesis during foetal lung development [9], and that in asthma, the EMTU drives airway remodelling essential for chronic disease (fig. 1) [14, 15]. Increased epithelial susceptibility and prolonged repair would serve to propagate the trophic response towards a chronic wound state in which mesenchymal cells (fibroblasts and smooth muscle cells) proliferate and alter their function to create the thickened and hyperresponsive airways characteristic of chronic disease (fig. 1). In the remodelled airway, mediators, cytokines and matrix molecules provide an optimal microenvironment for sustaining the chronic inflammatory response [18] and for providing a mechanism whereby more severe disease adopts an additional Th1 pattern involving neutrophils and pleiotropic cytokines, such as tumour necrosis factor (TNF)- $\alpha$ and interferon (IFN)- $\gamma$, which are able to induce more cell stress and tissue damage [19]. There is also recent evidence that Th1type cytokines contribute to childhood asthma $[20,21]$. 


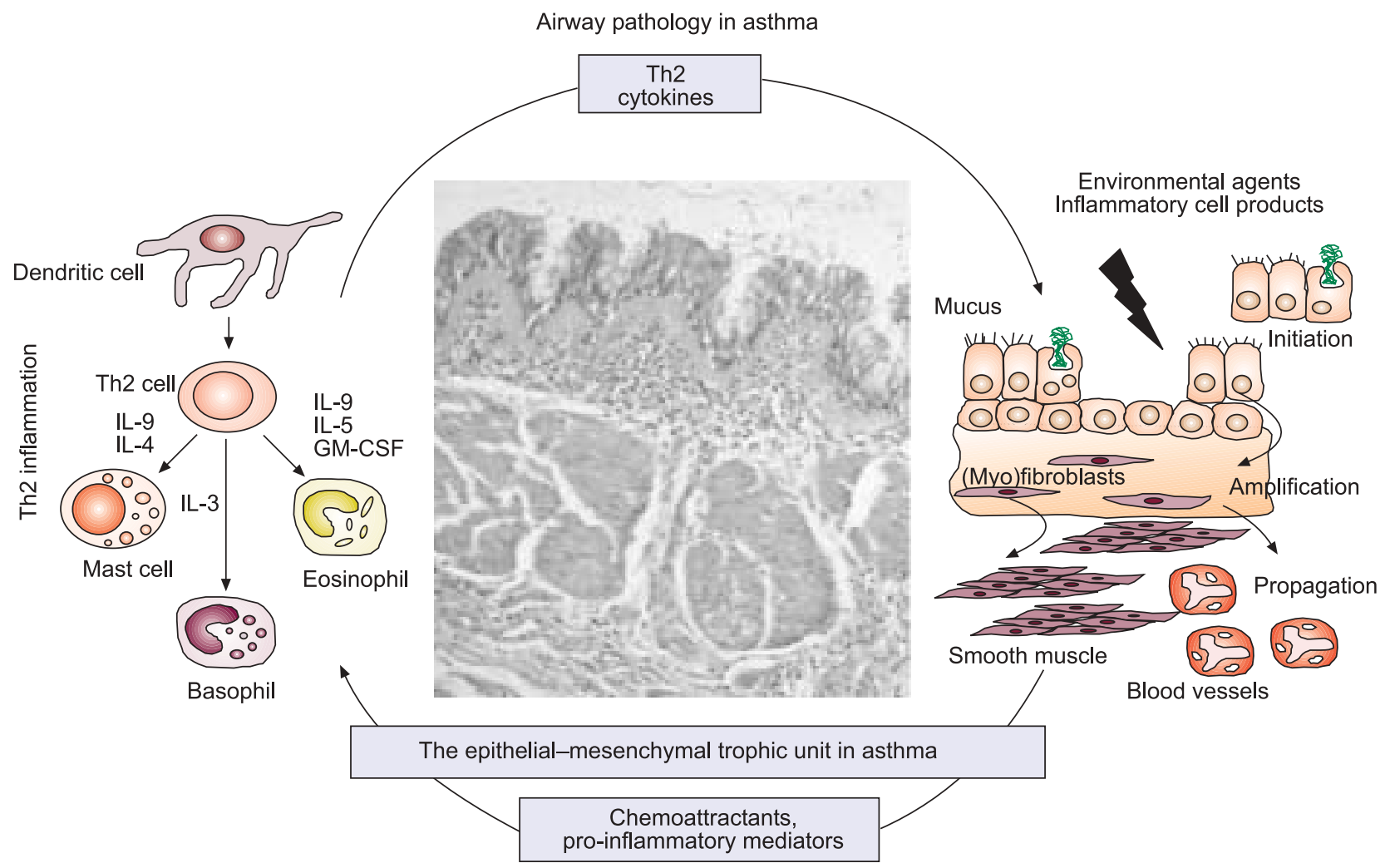

FIGURE 1. The role of the epithelial-mesenchymal trophic unit in asthma pathogenesis. Th: T-helper cell; IL: interleukin; GM-CSF: granulocyte-macrophage colonystimulating factor. Reproduced with permission from [15]

These ideas do not diminish the importance of Th2 cytokines in the airway dysfunction of asthma, but focus attention on the airway compartments that this and other key inflammatory pathways interact with that are important in disease expression, rather than focussing on whether cells are simply present or not. For example, mast cells present in smooth muscle are closely related to BHR [22], whereas eosinophils measured in blood or sputum relate more to disease exacerbations [23]. In the model shown in figure 1, Th2 cytokines play a key role in amplifying the tissue-specific features of asthma, such as goblet cell hyperplasia and transformation of fibroblasts to myofibroblasts. Placing airway tissue-specific events at the centre of asthma pathogenesis provides an explanation for the incomplete effectiveness of inhaled corticosteroids and the therapeutic synergy observed between inhaled corticosteroids and long-acting $\beta_{2}$-adrenoceptor agonists, the relatively poor correlation of submucosal eosinophil numbers with disease activity or chronicity, the presence of "remodelling" changes in the airways at the inception of asthma in the relative absence of eosinophils, the occurrence of asthma in the absence of atopy (as is prominent in occupational and aspirin-intolerant asthma) and the recently discovered efficacy of anti-TNF- $\alpha$ observed in patients with severe corticosteroid-dependent disease [24]. A key role of epithelial-mesenchymal communication in asthma is further endorsed by the observation that six of the seven asthma susceptibility genes discovered by positional cloning are localised to the EMTU, stating this in the form of the following hypothesis. The asthmatic state results from a combination of gene-gene and gene-environmental interactions localised to the conducting airways that involves susceptibility to injury and altered cell-cell communication between the epithelium and underlying fibroblast (mesenchymal stem cell) sheath in the airway wall. This causes activation of the EMTU, thereby initiating and propagating tissue remodelling and sustaining chronic inflammation.

Three major findings have led to this hypothesis, as follows.

1) Asthma is a disorder that is restricted to the conducting airways and does not result in an alveolitis, despite a spill-over of inflammatory cells into peri-bronchial alveoli in severe nocturnal asthma. Thus, in contrast with extrinsic allergic alveolitis, which involves airways and alveoli, the events of asthma are orchestrated by the conducting airways themselves, specifically the epithelium that represents the interface between the environment and the underlying mesenchymal compartment that translates epithelial signals into altered repair responses $[25,26]$, even though inhaled stimuli, such as allergens, pollutants and viruses, can penetrate into the alveoli $[27,28]$.

2) Much of the disordered airways dysfunction that occurs in chronic asthma is attributable to BHR, in which the airways contract too much and too easily in response to a wide variety of endogenously generated or environmental stimuli. In all but the mildest disease, refractoriness to corticosteroids [29], the beneficial effect of long-acting $\beta_{2}$-adrenoceptor agonists as supplementary therapy [30], the decline of lung function observed in chronic asthma at a population level over time [13] and the unmet clinical need [31] can be traced back to 
inflammatory responses acting on altered airway wall structure [32]. This is characterised by epithelial mucus metaplasia, thickening of the subepithelial lamina reticularis, deposition of interstitial (repair) collagens, proteoglycans and other matrix proteins throughout the airway wall (including smooth muscle) and alterations in the mass and orientation of the smooth muscle. These events lead to airway wall thickening, as observed by high-resolution computed tomography [25, 33, 34], an increase in peripheral lung resistance even in the presence of normal spirometry [35] and an increase in airway wall stiffness [36]. A second fundamental outcome of chronic asthma is BHR, which, as the disease becomes more severe and chronic, becomes refractory to corticosteroids [29]. As shown by the European Network for Understanding Mechanisms of Severe Asthma (ENFUMOSA) study [37], a key feature of more severe asthma is BHR combined with a lack of reversibility of airflow obstruction and hyperinflation that can be explained by a combination of airway wall remodelling and mucus hypersecretion involving all conducting airways, but stopping short of the respiratory bronchioles and alveoli. Recent work indicates that airway wall remodelling may be a natural protective response against repeated bronchospasm.

3) Environmental factors other than allergen sensitisation and exposure are important not only in disease inception but also in its severity and progression over time. These include exposures to ETS, both mainstream and sidestream [38], outdoor air pollutants (e.g. ozone, nitrogen dioxide and particles) [39], indoor air pollutants (e.g. volatile organic compounds [40]), a diet low in antioxidants [41] (especially vitamin E [42]), specific respiratory virus infections [43] and the direct enzymatic effects of inhaled allergens (e.g. Der p1 (a cysteine protease) [44] and pollen allergens (containing proteolytic enzymes and highly active nicotinamide adenosine dinucleotide phosphate oxidases)). From analyses of both cross-sectional and longitudinal studies in children and adults, the population attributable risk of atopy in the presence of current asthma is $<40 \%$. The population attributable risk falls to only $4 \%$ in relation to exposure to the indoor allergen, Der p1 [8]. This combined assessment, together with recent birth cohort studies, such as the German Multicentre Allergy Study $[6,45]$, indicates that atopy or allergen exposure requires vital interactions with independent factors in the primary causation of asthma and involves the susceptible airway itself. When compared with allergic rhinoconjunctivitis, this helps to explain the low efficacy of allergen-specific immunotherapy in asthma and the progressive loss of importance of allergen exposure as a cause of persistent asthma in adults as their disease consolidates over time. That atopy alone is insufficient to produce chronic asthma is strengthened by the failure (so far) of allergen-sensitisation and exposure models in animals (or humans) to aid in the development of novel asthma therapies other than those known to interfere with the acute allergen response, e.g. mast cell stabilisers, cystleukotriene (LT)1 antagonists and anti-immunoglobulin (Ig)E. Finally, all the recent effort that has been put into selectively targeting cytokines and adhesion molecules involved in the allergic pathway, e.g. soluble interleukin (IL)-4 receptor (Nuvance ${ }^{\circledR}$; Immunex, Seattle, WA, USA), anti-IL-4 monoclonal antibody, anti-IL-5 (e.g. mepolizumab), IFN- $\gamma$, IL-12 and very late activation antigen (VLA)- 4 antagonists, have so far all failed on entering clinical trials in asthma, despite producing marked effects on target cells in humans, e.g. reducing circulating, airway luminal and tissue eosinophils (table 1) [10]. While, in some cases, there maybe bioavailability or pharmacodynamic reasons for this, the fact that all of these therapies have proven so effective in a range of allergen-driven models in animals (including non-human primates), a serious question is raised as to whether the current animal "models" of asthma are relevant to the chronic airway events that underlie the human disease [46].

A radical new approach is needed to properly understand the combination of factors necessary for the cause(s) of chronic asthma and its progression beyond the simple concept of sequential allergen sensitisation and exposure. Reversible airflow obstruction and BHR have their origin in the way the formed elements of the airway, e.g. smooth muscle, respond to stimuli. While there is an undoubted and important interaction between airway inflammation and BHR, this is not a simple cause-and-effect relationship (fig. 1). Chronic airway inflammation involving T-cells, mast cells and eosinophils will only translate into BHR and variable airway flow obstruction if the underlying target tissue, which "hosts" the inflammatory response, provides the appropriate microenvironment that attracts and sustains the relevant inflammatory cells and remains susceptible to the mediators that they release [22, 47].

\section{THE EMTU AND AIRWAY WALL REMODELLING}

BHR is inherited independently of atopy and is linked to altered airway structure and wall thickening [48]. Although, in the past, this remodelling has been considered secondary to long-standing inflammation, airway biopsies from young children with asthma have shown extensive tissue restructuring at the onset of their disease $[49,50]$. Impaired baseline lung function and airway responsiveness shortly after birth in asymptomatic infants has also been demonstrated to predict asthma by school age in such children [51]. Evidence showing that environmental factors impact upon the airways to cause stress and damage, relevant to altered airways structure and function, includes the following. 1) Increased susceptibility of the airway epithelium to oxidant stress and a greater propensity to propagate respiratory viruses that persist through passage in cell culture. 2) Prolonged epithelial repair due to an imbalance between epidermal growth factor and transforming growth factor (TGF)- $\beta$ signalling pathways and interference with cell cycling. 3) Evidence that the altered epithelium communicates with the underlying mesenchyme to create a trophic unit that propagates and amplifies remodelling from the epithelial surface to the submucosa via effector (myo)fibroblasts. 4) Localisation of Th2 inflammation being favoured by the EMTU enabling Th2 cytokines, such as granulocyte-macrophage colony-stimulating factor, and IL-4, -9 and -13 , to work in concert to maintain inflammation and drive remodelling "responses" (fig. 1) [5, 52].

\section{THE GENETIC BASIS FOR ASTHMA}

While asthma is multigenetic, studies conducted on founder and mixed populations point to a few genes with moderate effect rather than many genes with small effects [53]. Over the last decade, candidate gene and positional cloning efforts have identified novel genetic variations that have been associated 
with asthma or its partial phenotypes. While some of these are more closely linked to atopy and allergen-specific responses, e.g. human lymphocyte antigen (HLA) restriction and polymorphic variation in T-cell receptor (TCR) genes, others relate much more closely to disordered airway function independent of atopy. Segregation analysis has reinforced the view that, although atopy and BHR are correlated, they appear to be under separate genetic control [53-55]. Two approaches have been used to identify asthma-related genes: candidate gene allelic association studies, in which molecules are selected on the basis of their known role in pathophysiology, and positional cloning (reversed genetics), in which linkage, physical and linkage disequilibrium mapping and association studies are used to first identify chromosomal regions of interest and then to pinpoint genes within them responsible for the signal without prior knowledge of the gene's function [53]. Both of these approaches provide opportunities for uncovering novel molecules in disease pathogenesis and will be considered separately.

\section{Candidate gene association studies}

Family based and case-control association studies have proven to be powerful tools to determine whether a specific single nucleotide polymorphism (SNP) within the promoter region of a gene encoding a specific protein of known function for controlling its production (promoter) increases the risk of asthma, a partial disease phenotype (e.g. BHR or IgE) or response to a therapy. Although a number of these involve the "pro-allergic" immunological pathways, e.g. HLA, TCR, cytotoxic T-lymphocyte-associated antigen (CTLA)-4 and Th2 cytokines and their receptors, or potentially protective "antiallergic" molecules, e.g. CD14, Toll-like receptors (TLR)-4 and 9 [54], there are others that do not [56]. Candidate genes more closely associated with airway function (e.g. BHR) and disease severity (e.g. treatment requirements) include the $\beta_{2}$-adrenoceptor (Gly 16 Arg, Gln 27 Gly and Thr 64 Ile) [57], TGF- $\beta$ (C509T, 72 Ins C, T869C and G915C) [58, 59], LT C4 synthase (A-444C) [60], glutathione-S-transferase (GST P1: Val $105 \mathrm{Leu})$ [61], TNF- $\alpha$ (G-308A), TNF- $\beta$ (LT $\alpha$ NcoI) [62] and neuronal NOS $\left(\mathrm{CA}_{18}\right.$ allele) [63]. In other cases, genetic variation in specific genes have effects on both immunological/inflammatory and structural cells, such as IL-4, -9, -13, and their respective receptors and intracellular signalling molecules, such as signal transducer and activator of transcription (STAT)-6, suppressor of cytokine signalling (SOCS)-1, SOCS box and, most recently, the identification of TLRs on epithelial cells and smooth muscle [64].

While for a reasonable number of these gene SNP associations have been confirmed in different populations, there have been others that have not been replicated $[2,56]$. It is of fundamental importance that a systematic approach is taken to either confirm or refute positive associations and to determine which, if any, of these genes are implicated in disease origin and progression. This last step can only be undertaken in large prospective birth cohorts where there is good longitudinal phenotypic data and adequate power. For most studies, single SNPs or a few SNP combinations (haplotypes) within a single gene have been studied in relation to disease phenotype, but what is clearly needed is a more ambitious analysis of haplotype and epigenetic interactions, especially for candidate molecules involved in linear pathways such as IL-4 $\rightarrow$ IL- $4 \mathrm{R} \rightarrow$ STAT-6 $\rightarrow$ cell response [65]. However, this approach requires access to large, well-characterised cohorts.

\section{Disease linkage analysis and positional cloning}

There have been at least eight genome-wide screens published using microsatellite markers spaced at intervals across all chromosomes to establish linkage with asthma or its partial phenotypes. Linkage has been reported to regions on 23 chromosomes but only relatively recently have positional cloning efforts identified putative novel genes at these sites [65]. The first of these was conducted on a multi-ethnic founder population in Tristan da Cunha [66]. Using 270 microsatellite markers, two distinct loci "wheeze 1 " and "wheeze 2 " on chromosome 11p13, were identified between the markers D11S935-D11S1776 with strong linkage to BHR and asthma $(p<0.0001)$ [67]. Physical mapping and DNA sequencing followed by family and case-control association studies using both the Tristan da Cunha population and a mixed population of European descendants in Toronto, Canada, identified the genes as encoding two related proteins designated ETS-2 and ETS-3, which are members of a transcription factor family $[67,68]$. Further studies on ETS-3 revealed that basal expression was restricted to epithelial cells with a secretory capacity including the airway epithelium. ETS-3 exists in three isoforms due to alternative splicing and is thought to be involved in directing epithelial cell differentiation towards a mucus-secreting phenotype [69]. The A-140 G variant has been shown to affect CCAAT enhancer-binding protein binding to the ETS-3 promoter. ETS-3 has also been shown to be upregulated in fibroblasts and smooth muscle when exposed to pro-inflammatory cytokines, where it serves as a transcriptional repressor [70]. Recently, a study undertaken by GlaxoSmithKline has confirmed the association of ETS-2 and ETS-3 with asthma in separate outbred populations [71], whereas a third recently published USA study has not [70]. This discrepancy further emphasises the need for further replication studies in larger populations.

A high proportion of the genome-wide screens have identified chromosome 5q31-34 as a key region of interest for asthma. Apart from the IL-4 gene cluster, the $\beta_{2}$-adrenoceptor and the cortiocosteroid receptor, this region contains the gene encoding of a serine protease inhibitor, Kazal type 5 (SPINK 5). Several mutations in the SPINK 5 gene occur through frame-shift mutations and alternative splicing leading to Netherton's syndrome, a rare form of autosomal recessive disorder characterised by defective epithelial function with features of eczema [72]. Within SPINK 5, 32 SNPs have been identified, six of which result in amino acid changes. One of these (Glu420Lys) has been reported to be strongly associated with asthma, and eczema, both in the UK [73] and in separate German populations [74]. SPINK 5 is restricted in its expression to the epithelium, where it serves an important protective role against proteases, such as those secreted by mast cells or present in allergen extracts [75]. A second, nonimmunological asthma gene has recently been identified using a collection of Dutch asthmatic families. Collaboration between the University of Groningen (Groningen, the Netherlands), Wake Forest University (Winston-Salem, NC, USA) and Novartis has identified the protocadherin-1 gene $(\mathrm{PCDH}-1)$ in chromosome 
$5 q 31$ to be associated with BHR. $P C D H-1$ is expressed in lung tissue, especially the bronchial epithelium, where it is involved in calcium-dependent cell adhesion [76]. It is tempting to speculate that variants of this gene lead to the reduced epithelial integrity characteristic of asthma.

An important recent breakthrough in the genetics of asthma has been the identification of a disintegrin and metalloproteinase $(A D A M) 33$ as a major candidate gene for asthma and BHR in a positional cloning effort involving $460 \mathrm{UK}$ and USA families enriched for asthma [77]. Using multi-point linkage analysis and 401 microsatellite markers at a density of $\sim 9$ centimorgans (cM), suggestive evidence for linkage (multipoint logarithm of odds score (MLS) 2.24) was found on chromosome 20p13 at $9.99 \mathrm{cM}$. The addition of further markers increased the MLS at marker D20S482 $(12.1 \mathrm{cM})$, which further increased to 3.93 when BHR was included in the definition of asthma. Physical mapping and direct cDNA selection identified 40 genes under the peak of linkage that were subsequently sequenced to identify SNPs for use in later association studies. Case-control and family based association and linkage disequilibrium analyses identified $A D A M 33$ as being responsible for the linkage signal, the significance of which strengthened when haplotypes were used in the association (eight SNP combinations; $\mathrm{p}=0.00003-0.005$ ) [59]. $A D A M 33$ is among the most recently reported members of the $A D A M$ gene family of $\mathrm{Zn}^{+}$dependent matrix metalloproteinases, which now number 40. It is composed of eight domains, the first six of which encode signal, pro-, catalytic, disintegrin, cysteine-rich and epidermal growth factor-like sequences, followed by a transmembrane domain and cytoplasmic tail with cell signalling sequences. $A D A M 33$ is restricted in its expression to mesenchymal cells, such as fibroblasts and smooth muscle, where it is probable it functions to influence airway wall remodelling and BHR. An ADAM33 on mouse chromosome 2 (syntenic to human chromosome 20) [78] has also been linked to BHR in this animal. $A D A M 33$ contains $\geqslant 56$ SNPs, of which the majority associated with asthma and BHR are found in introns controlling RNA stability and alternative splicing. In airway fibroblasts and smooth muscle, six alternatively spliced variants of $A D A M 33$ have been discovered [79]. Under certain circumstances, a full-length $A D A M 33$ gene can also be transported to the cell membrane where it exerts proteolytic activity [80]. The $A D A M 33$ gene is also preferentially expressed during branching morphogenesis in the mouse and human lung, suggesting an important function within the EMTU linked to lung development. It is clearly of great importance that more is found out about the normal function of ADAM33 and how polymorphic variations may predispose to asthma [81]. Association of the ADAM33 gene with asthma has now been confirmed in Caucasian-, African- and Hispanic-Americans in the Collaborative Study on the Genetics of Asthma [82] and separate populations in the Netherlands [82], Germany [83], Korea [84] and Japan [85] and in a large meta-analysis involving Icelandic, Mexican and Puerto Rican, as well as European, populations [86]. In this latter study, there were several populations which, when analysed alone, failed to reveal significance but together resulted in strong association, thereby emphasising the importance of combining data. Furthermore, polymorphisms in this gene are associated with lung function decline in asthmatics, supporting a role in remodelling [87].
Following on from a genome-wide study showing strong linkage of asthma and eczema to chromosome 2q14, ALLEN et al. [88] have recently described a novel candidate gene linked to asthma close to the marker D2S308 and identified as the S9B subfamily of prolyl-oligopeptidase family that includes the dipeptidyl peptidase (DPP)4 (CD26) and DPP10. DPP4 is expressed by epithelial cells where it functions as an adhesion receptor for collagen and fibronectin involved in epithelial repair. In April 2004, a further novel asthma gene was reported that had been identified by positional cloning; this gene was an orphan G-protein-coupled receptor (GPRA) encoded on chromosome $7 \mathrm{p}$ that showed distinct distribution of protein isoforms in bronchial biopsies from healthy (A isoform; epithelial location) and asthmatic (B isoform; smooth muscle location) individuals [89]. Finally, in the same families in which $A D A M 33$ was first discovered, a second gene, MUC8, on chromosome 12q23-ter has been identified following replication of linkage in this chromosomal region in a number of different populations [90]. Mucin 8 is one of 18 mucin genes but, unlike many, it shares with MUC5AC and 5B the property of being secreted by airway epithelium, being highly glycosylated, being regulated by IL-1 $\beta$ and IL-13, and being preferentially expressed in allergic airway disease [91, 92]. Among novel asthma susceptibility genes discovered is one involved in eicosanoid actions: PTGDR on 14q 22.1 encodes the prostaglandin (PG)D2 receptor DP1, with wide expression on smooth muscle, blood vessels and mast cells [93]. It is noteworthy that this gene, along with all genes that have so far been identified through positional cloning in asthma, has a cellular provenance that is largely restricted to epithelial or mesenchymal cells with functions linked to activation of the EMTU and its downstream consequences. NicOLAE et al. [94] have also fine mapped the human lymphocyte antigen (HLA)$\mathrm{G}$ as an asthma susceptibility gene on chromosome 6p21. It has been further shown that in the lung, this gene is most highly expressed by epithelial cells. Of the different forms of HLA-G described, expression in the lung was limited to the soluble isoform (G1). Differing from other HLA molecules, HLA-G is a major histocompatibility complex class 1 molecule involved in regulating the type and level of chronic forms of inflammation and specifically the Th1/Th2 T-cell balance [95].

\section{GENE-GENE AND GENE-ENVIRONMENT INTERACTIONS}

The complexities of the human genome embrace important gene-gene as well as gene-environment interactions. CoLILLA et al. [96] have recently reported marked interactions between two chromosomal regions linked to asthma and its phenotypes (conditional analysis). For example, a linkage on chromosome 20p13 that contains ADAM33 increased from a MLS of 0.89 to 5.9 when conditioned for linkage to chromosome 2 . At the level of an individual gene, strong interactions have been shown for genes operating on a single metabolic pathway, e.g. IL-4 and STAT6 [97]. Within a single gene, polymorphic variations involving several sites that include introns and the 3 '-UTR are likely to account for the subtle changes in gene function associated with complex disorders. Good examples are ADAM33, DPP10, PCDH1 and CTLA-4, all of which contain many SNPs that interact as haplotypes. Of considerable relevance to asthma susceptibility is the recognition that exposure to specific environmental factors is a key component 
to the induction or repression of asthma-related genes. One of the most widely quoted examples is the interaction of endotoxin with TLR-4, with impacts on shaping the subsequent adaptive immune response as well as influencing effector cell functions, such as epithelial and smooth muscle cells. Polymorphic variation in TLR-4 is associated with asthma and atopy, and it is highly likely that other TLRs will exhibit similar polymorphic associations with other environmental stimuli, e.g. CpG (TLR-9) and dsRNA (TLR-3). Maternal tobacco smoking is a well-established risk factor for asthma in offspring. An exciting recent observation by KOPPELMAN [98] in Groningen, the Netherlands, is that maternal smoking greatly increases the strength of the linkage signal on chromosome 5q31-34 to asthma in the offspring. Polymorphic variation in candidate genes known to be involved in asthma, such as TNF308 and GSTM1, are also predictors of enhanced airway responses to air pollutants that in themselves have important impacts on lung growth maturation [99]. These studies raise the important point that early life environmental factors, such as passive smoking, diet, pollutant exposure and viral infections, may all have a perverse effect on the developing lung in childhood, as recently highlighted by the WHO report "Systematic Review of Health Aspects of Air Pollution in Europe" [100].

As demonstrated by work already reported by partners in Gene-Environmental Interactions in the Origins and Progression of Asthma, the environmental data in the cross-sectional and cohort studies can be incorporated into both linkage and association studies. Longitudinal data sets that include physiological measures (e.g. specific airway resistance and forced expiratory volume in one second) have also proven to be of considerable value when refining the potential role of a candidate gene, such as $A D A M 33$, in predicting reduced lung function in young children born of asthmatic and allergic parents or a more rapid loss of baseline lung function in chronic asthma over time.

\section{FUNCTIONAL ANALYSIS AND VALIDATION OF SELECTED ASTHMA SUSCEPTIBILITY MOLECULES}

Following the identification of susceptibility genes for asthma, a key step to understanding how they interact to produce disease is the use of in vitro human cell culture systems to assess their function(s) in relation to polymorphic variance, i.e. translational research (fig. 2). Based on current knowledge, genetic variability exists in the coding and/or regulatory regions of genes coding for the receptors and downstream signalling molecules at which agents that control airway calibre and remodelling act. Through these pathways, genetic variability in key airway targets will contribute to disease severity, chronicity and treatment responses. For example, persistent activation of the nuclear factor (NF)- $\kappa \mathrm{B}$ is crucially involved in the ongoing inflammation and remodelling observed in severe asthma [101, 102]. Thus, in a specific cell type, it is important to determine at which level the NF- $\kappa B$ activation pathway is affected by evaluating the levels of p65, an inhibitor of the nuclear transcription factor NF- $\kappa \mathrm{B}(\mathrm{I} \kappa \mathrm{B} \alpha)$, phosphorylated $\mathrm{I} \kappa \mathrm{B} \alpha$ and an inhibitor of $\kappa \mathrm{B}$ kinase $\beta$ (IKK $\beta$ ). Using cell and molecular biological techniques applied to primary cell cultures and cell lines, it is possible to assess the influence of polymorphic variation in specific molecules on overall cell function using well-validated read-outs in the absence and presence of relevant environmental exposures (e.g. ETS, air pollutants, respiratory viruses, Toll receptor ligands).

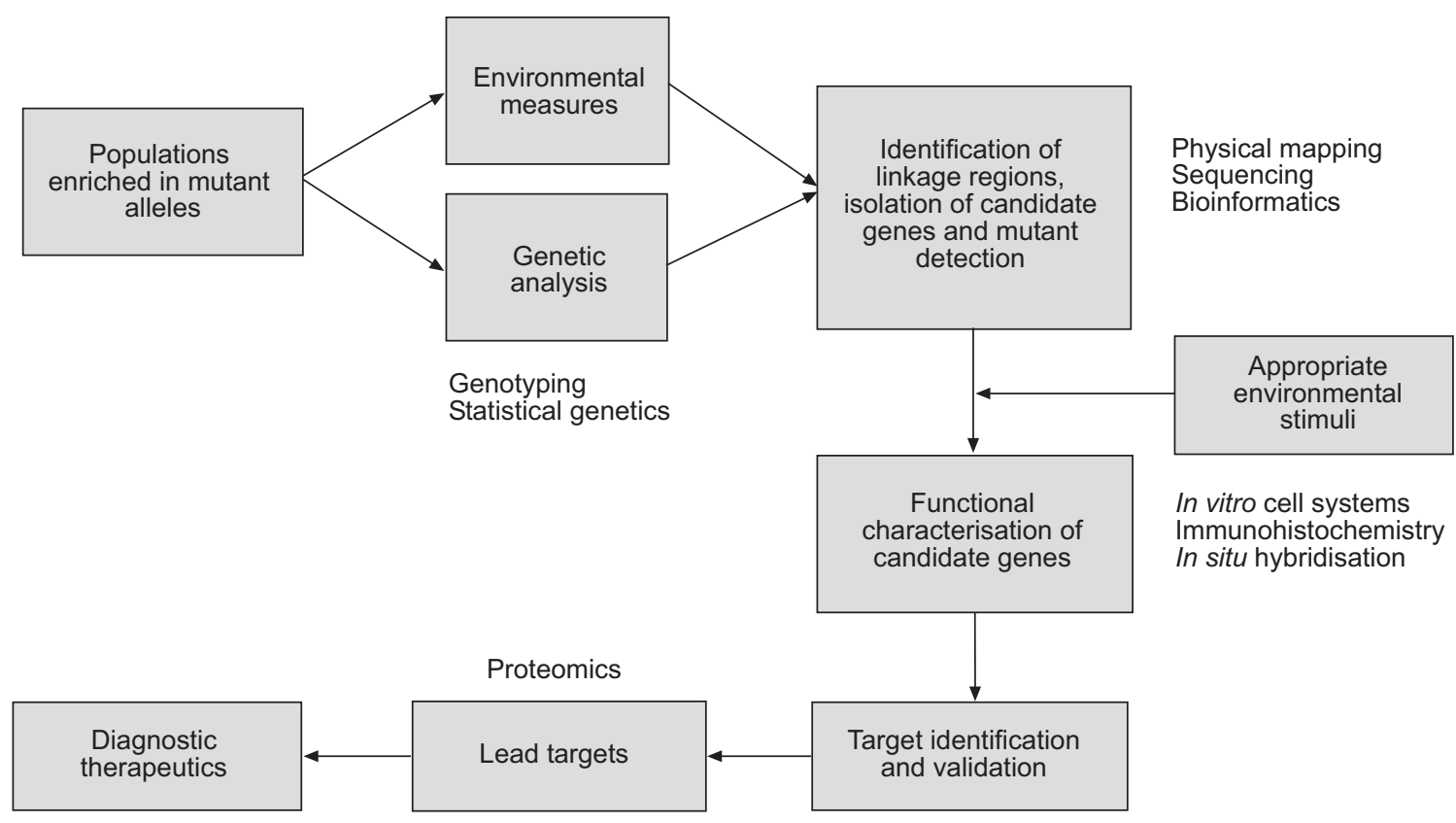

FIGURE 2. Searching for susceptibility genes to uncover the aetiology of complex diseases. 
Transfection of cells can be achieved using adenoviral, retroviral or HIV trans-acting transcriptional activator peptide vectors with gain and loss of function strategies; RNAi, and antisense and target-directed monoclonal antibodies can be used to assess function. In complex disease, there are increasing numbers of intronic noncoding and 3'-UTR SNPs that influence RNA stability, transport and gene-splicing that appear to be important disease-related candidates. Alternatively, spliced variants can be identified using appropriate primers and Taqman PCR or 5'-RACE (rapid amplification of 5' complementary DNA ends) approaches, with assays being established to assess their function after gene transfection. In the case of asthma, subtypes such as aspirin-intolerant asthma, polymorphic variation in the eocosanoid synthetic enzymes, mediator receptors and downstream signalling pathways can be studied in cells and tissues obtained from relevant patients compared with matched controls. In vitro models can also be used to assess the role of specific candidate genes in susceptibility to respiratory virus infection, cell death, viral shedding and activation of the EMTU. In addition to in vitro assays, the cellular provenance and extent of expression of candidate molecules can be defined in airway cells obtained by bronchial biopsy, brushing and induced sputum by in situ hybridisation and immunohistochemistry using appropriate historical tissue biobanks and ongoing collections provided by the consortium, and also biopsy samples obtained from children undergoing bronchoscopy for reasons other than their asthma.

\section{ESTABLISHING CAUSATIVE LINKS BETWEEN SPECIFIC BIOMARKERS AND SUBTYPES OF ASTHMA}

A constant theme of the present article is the principle that asthma is not a homogeneous disease but a condition influenced by interactions between genetic and environmental factors, as has been shown for other complex diseases. In trying to understand the cellular and molecular basis for this heterogeneity, asthma biobanks comprised of mild and severe asthmatic patients and normal controls provide a unique opportunity to relate specific molecular targets, identified from the allelic association and functional studies, to subtypes of well-characterised asthma using tissue and biological fluids and to correlate these with clinical and physiological indices.

\section{PROGRESSION OF CANDIDATE MOLECULES INTO DIAGNOSTIC TESTS AND NOVEL THERAPEUTICS}

Having defined the association and potential relevance of specific molecules in the origins and/or progression of asthma, these will need to be exploited in order to develop novel diagnostic tests based on DNA SNP combinations, e.g. in $A D A M 33$, and specific proteins in biological fluids, such as sputum and serum. The selected biomarkers used either alone or in combination as disease "fingerprints" can then be tested on the various birth cohorts to determine their predictive capacity for asthma and their capacity to identify asthma subtypes with differing natural history, response to conventional treatments and prognosis. Equally, the application of molecular-based targeting using monoclonal antibodies, soluble receptors and sRNAi, as well as medicinal chemistry, will create the opportunity to discover new drugs that are closer to the disease cause. The real strength of this modern technology lies in the "bench-to-bedside" approach in order to understand the molecular mechanisms of asthma and, using this information, to take forward, in a timely and imaginative manner, the identification of novel molecules of great value in developing new ways of predicting and diagnosing this disease and targeting novel pathways closer to the disease origin that will lead to its prevention and hopefully its cure [103].

\section{REFERENCES}

1 Bel EH. Clinical phenotypes of asthma. Curr Opin Pulm Med 2004; 10: 44-50.

2 Kauffmann F. Post-genome respiratory epidemiology: a multidisciplinary challenge. Eur Respir J 2004; 24: 471-480.

3 British Thoracic Society, Scottish Intercollegiate Guidelines Network (SIGN). British guidelines on the management of asthma. Thorax 2003; 58: Suppl. 1, 1-94.

4 Sheffer A. Global Initiative for Asthma. NHLBI/WHO Workshop Report. Bethesda, National Heart Lung and Blood Institute, 1995.

5 Holgate ST, Puddicombe SM, Mullings RE, et al. New insights into asthma pathogenesis. Allergy Clin Immunol Int 2004; 16: 196-201.

6 Nickel R, Lau S, Niggermann B, et al. Messages from the German Multicentre Allergy Study. Paediatr Allergy Immunol 2002; 13: Suppl. 15, 7-10.

7 Pearce N, Pekkanen J, Beasley R. How much asthma is really attributable to atopy? Thorax 1999; 54: 268-272.

8 Pearce N, Douwes J, Beasley R. Is allergen exposure the major primary cause of asthma? Thorax 2000; 55: 424-431.

9 von Mutius E, Sears MR. Risk factors for development of asthma. Eur Respir Mon 2003; 8: 57-73.

10 Barnes PJ. New directions in allergic diseases: mechanism-based anti-inflammatory therapies. J Allergy Clin Immunol 2000; 106: 5-16.

11 Warner JA. Can we prevent allergies and asthma? Allergy Clin Immunol Int 2004; 16: 186-191.

12 Kasahara K, Shiba K, Ozawa T, Okuda K, Adachi M. Correlation between the bronchial subepithelial layer and whole airway wall thickness in patients with asthma. Thorax 2002; 57: 242-246.

13 Lange P, Parner J, Vestbo J, Schnohr P, Jensen G. A 15year follow-up study of ventilatory function in adults with asthma. N Engl J Med 1998; 339: 1194-1200.

14 Holgate ST, Davies DE, Lackie PM, Wilson SJ, Puddicombe SM, Lordan JL. Epithelial-mesenchymal interactions in the pathogenesis of asthma. J Allergy Clin Immunol 2000; 105: 193-204.

15 Davies DE, Wicks J, Powell RM, Puddicombe SM, Holgate ST. Airway remodelling in asthma - new insights. J Allergy Clin Immunol 2003; 111: 215-225.

16 Sinha A, Nightingale J, West KP, Berlanga-Acosta J, Playford RJ. Epidermal growth factor enemas with oral mesalamine for mild-to-moderate left-sided ulcerative colitis or proctitis. N Engl J Med 2003; 349: 350-357.

17 Behan PO, Chaudhuri A, Roep BO. The pathogenesis of multiple sclerosis revisited. J R Cell Physicians Edinb 2002; 32: 244-265.

18 Davies DE, Holgate ST. Asthma: the importance of epithelial mesenchymal communication in pathogenesis. 
Inflammation and the airway epithelium in asthma. Int J Biochem Cell Biol 2002; 34: 1520-1526.

19 Wasserman S, Dolovich J, Conway M, Marshall JS. TNF $\alpha$ dysregulation in asthma: relationship to ongoing corticosteroid therapy. Can Respir J 2000; 7: 229-237.

20 Heaton T, Rowe J, Turner S, et al. An immunoepidemiological approach to asthma: identification of in vitro T-cell response patterns associated with different wheezing phenotypes in children. Lancet 2005; 365: 142-149.

21 Umetsu DT. Revising the immunological theories of asthma and allergy. Lancet 2005; 365: 98-100.

22 Brightling CE, Bradding P, Symon FA, Holgate ST, Wardlaw AJ, Pavord ID. Mast-cell infiltration of airway smooth muscle in asthma. N Engl J Med 2002; 346: 1699-1705.

23 Green RH, Brightling CE, McKenna S, et al. Asthma exacerbations and sputum eosinophil counts: a randomised controlled trial. Lancet 2002; 360: 1715-1721.

24 Babu KS, Davies DE, Holgate ST. Role of tumor necrosis factor alpha in asthma. Immunol Allergy Clin North Am 2004; 24: 583-585.

25 Niimi A, Matsumoto H, Takemura M, Ueda T, Chin K, Mishima M. Relationship of airway wall thickness to airway sensitivity and airway reactivity in asthma. Am J Respir Crit Care Med 2003; 168: 983-988.

26 Shaw TJ, Wakely SL, Peebles CR, et al. Endobronchial ultrasound to assess airway wall thickening: validation in vitro and in vivo. Eur Respir J 2004; 23: 813-817.

27 Holgate ST, Lackie PM, Davies DE, Roche WR, Walls AF. The bronchial epithelium as a key regulator of airway inflammation and remodelling in asthma. Clin Exp Allergy 1999; 29: Suppl. 2, 90-95.

28 Knight D. Increased permeability of asthmatic epithelial cells to pollutants. Does this mean that they are intrinsically abnormal? Clin Exp Allergy 2002; 32: 1263-1265.

29 Chung KF, Stirling RG, Chanez P, Godard P. Severe therapy resistant asthma. In: Asthma. Eur Respir Mon 2003; 8; 312-338.

30 Woolcock A, Lundback B, Ringdal N, Jacques LA. Comparison of addition of salmeterol to inhaled steroids with doubling of the dose of inhaled steroids. Am J Respir Crit Care Med 1996; 153: 1481-1488.

31 Bjermer L. History and future perspectives of treating asthma as a systemic and small airways disease. Respir Med 2001; 95: 703-719.

32 Bai TR, Cooper J, Koelmeyer T, Pare PD, Weir TD. The effect of age and duration of disease on airway structure in fatal asthma. Am J Respir Crit Care Med 2000; 162: 663-669.

33 Little SA, Sproule MW, Cowan MD, et al. High resolution computed tomographic assessment of airway wall thickness in chronic asthma: reproducibility and relationship with lung function and severity. Thorax 2002; 57: 247-253.

34 Niimi A, Matsumoto H, Amitani R, et al. Airway wall thickness in asthma assessed by computed tomography. Relation to clinical indices. Am J Respir Crit Care Med 2000; 162: 1518-1523.

35 Wagner EM, Liu MC, Weinmann GG, Permutt S, Bleecker ER. Peripheral lung resistance in normal and asthmatic subjects. Am Rev Respir Dis 1990; 141: 584-588.
36 Ward C, Johns DP, Bish R, et al. Reduced airway distensibility, fixed airflow limitation, and airway wall remodeling in asthma. Am J Respir Crit Care Med 2001; 164: 1718-1721.

37 The ENFUMOSA cross-sectional European multicentre study of the clinical phenotype of chronic severe asthma, European Network for Understanding Mechanisms of Severe Asthma. Eur Respir J 2003; 22: 470-477.

38 Strachan DP, Cook DG. Health effects of passive smoking. 6. Parental smoking and childhood asthma: longitudinal and case-control studies. Thorax 1998; 53: 204-212.

39 Viegi G, Baldacci S. Epidemiological studies of chronic respiratory conditions in relation to urban air pollution in adults. In: The Impact of Air Pollution on Respiratory Health. Eur Respir Mon 2002; 7: 1-16.

40 Brunekreef B. The great indoors. Thorax 2004; 59: 729-730.

41 Shaheen SO, Sterne JA, Thompson RL, Songhurst CE, Margetts BM, Burney PG. Dietary antioxidants and asthma in adults: population-based case-control study. Am J Respir Crit Care Med 2001; 164: 1823-1828.

42 Devereux G, Seaton A. Why don't we give chest patients dietary advice? Thorax 2001; 56: Suppl. 2, ii15-ii22.

43 Stein RT, Sherrill D, Morgan WJ, et al. Respiratory syncytial virus in early life and risk of wheeze and allergy by age 13 years. Lancet 1999; 354: 541-545.

44 Sharma S, Lackie PM, Holgate ST. Uneasy breather: the implications of dust mite allergens. Clin Exp Allergy 2003; 33: $163-165$.

45 Lau S, Illi S, Sommerfeld C, et al. Early exposure to housedust mite and cat allergens and development of childhood asthma: a cohort study. Multicentre Allergy Study Group. Lancet 2000; 356: 1392-1397.

46 Persson CG. Con: mice are not a good model of human airway disease. Am J Respir Crit Care Med 2002; 166: 6-7.

47 Wardlaw AJ, Brightling CE, Green R, Woltmann G, Bradding P, Pavord ID. New insights into the relationship between airway inflammation and asthma. Clin Sci (Lond) 2002; 103: 201-211.

48 Vignola AM, Kips J, Bousquet J. Tissue remodeling as a feature of persistent asthma. J Allergy Clin Immunol 2000; 105: 1041-1053.

49 Pohunek P, Roche WR, Tarzikova J, Kurdmann J, Warner JO. Eosinophilic inflammation in the bronchial mucosa in children with bronchial asthma. Eur Respir $J$ 1998; 11: Suppl. 25, 160s.

50 Payne DN, Rogers AV, Adelroth E, et al. Early thickening of the reticular basement membrane in children with difficult asthma. Am J Respir Crit Care Med 2003; 167: 78-82.

51 Joseph-Bowen J, de Klerk NH, Firth MJ, Kendall GE, Holt PG, Sly PD. Lung function, bronchial responsiveness, and asthma in a community cohort of 6-year-old children. Am J Respir Crit Care Med 2004; 169: 850-854.

52 Olman MA. Epithelial cell modulation of airway fibrosis in asthma. Am J Respir Cell Mol Biol 2003; 28: 125-128.

53 Holloway JW, Jongepier H, Beghé B, Koppelmann GH, Holgate ST, Postma DS. The genetics of asthma. In: Asthma. Eur Respir Mon 2003; 8: 1-25.

54 Otsu A, Shirakawa T. Genetic and environmental factors of atopy. Allergol Int 2002; 51: 213-219. 
55 Pin I, Siroux V, Cans C, et al. Familial resemblance of asthma severity in the EGEA* study. Am J Respir Crit Care Med 2002; 165: 185-189.

56 Hoffjan S, Nicolae D, Ober C. Association studies for asthma and atopic diseases: a comprehensive review of the literature. Respir Res 2003; 4: 14.

57 D'Amato M, Vitiani LR, Petrelli G, et al. Association of persistent bronchial hyperresponsiveness with beta2adrenoceptor (ADRB2) haplotypes. A population study. Am J Respir Crit Care Med 1998; 158: 1968-1973.

58 Buckova D, Izakovicova HL, Benes P, Znojil V, Vacha J. TGF-beta1 gene polymorphisms. Allergy 2001; 56: 1236-1237.

59 Hobbs K, Negri J, Klinnert M, Rosenwasser LJ, Borish L. Interleukin-10 and transforming growth factor-beta promoter polymorphisms in allergies and asthma. Am J Respir Crit Care Med 1998; 158: 1958-1962.

60 Sanak M, Pierzchalska M, Bazan-Socha S, Szczeklik A. Enhanced expression of the leukotriene C(4) synthase due to overactive transcription of an allelic variant associated with aspirin-intolerant asthma. Am J Respir Cell Mol Biol 2000; 23: 290-296.

61 Fryer AA, Bianco A, Hepple M, Jones PW, Strange RC, Spiteri MA. Polymorphism at the glutathione S-transferase GSTP1 locus. A new marker for bronchial hyperresponsiveness and asthma. Am J Respir Crit Care Med 2000; 161: 1437-1442.

62 Noguchi E, Yokouchi Y, Shibasaki M, et al. Association between TNFA polymorphism and the development of asthma in the Japanese population. Am J Respir Crit Care Med 2002; 166: 43-46.

63 Grasemann H, Yandava CN, Storm van's GK, et al. A neuronal NO synthase (NOS1) gene polymorphism is associated with asthma. Biochem Biophys Res Commun 2000; 272: 391-394.

64 Bals R, Hiemstra PS. Innate immunity in the lung: how epithelial cells fight against respiratory pathogens. Eur Respir J 2004; 23: 327-333.

65 Wills-Karp M, Ewart SL. Time to draw breath: asthmasusceptibility genes are identified. Nat Rev Genet 2004; 5: 376-387.

66 Zamel N, McClean PA, Sandell PR, Siminovitch KA, Slutsky AS. Asthma on Tristan da Cunha: looking for the genetic link. The University of Toronto Genetics of Asthma Research Group. Am J Respir Crit Care Med 1996; 153: 1902-1906.

67 Tugores A, Le J, Sorokina I, et al. The epithelium-specific ETS protein EHF/ESE-3 is a context-dependent transcriptional repressor downstream of MAPK signaling cascades. J Biol Chem 2001; 276: 20397-20406.

68 Kas K, Finger E, Grall F, et al. ESE-3, a novel member of an epithelium-specific ets transcription factor subfamily, demonstrates different target gene specificity from ESE-1. J Biol Chem 2000; 275: 2986-2998.

69 Silverman ES, Baron RM, Palmer LJ, et al. Constitutive and cytokine-induced expression of the ETS transcription factor ESE-3 in the lung. Am J Respir Cell Mol Biol 2002; 27: 697-704.

70 Baron RM, Palmer LJ, Tantisira K, et al. DNA sequence variants in epithelium-specific ETS-2 and ETS-3 are not associated with asthma. Am J Respir Crit Care Med 2002; 166: 927-932.

71 Sreeckumar GP, Binnie CG, Carden EG, et al. Association of asthma and related phenotypes with ASTH-I/J genes on chromosome 11p in Caucasians. J Am Soc Hum Gen 1974; A354: 2000.

72 Chavanas S, Bodemer C, Rochat A, et al. Mutations in SPINK5, encoding a serine protease inhibitor, cause Netherton syndrome. Nat Genet 2000; 25: 141-142.

73 Walley AJ, Chavanas S, Moffatt MF, et al. Gene polymorphism in Netherton and common atopic disease. Nat Genet 2001; 29: 175-178.

74 Kabesch M, Carr D, Weiland SK, von Mutius E. Association between polymorphisms in serine protease inhibitor, kazal type 5 and asthma phenotypes in a large German population sample. Clin Exp Allergy 2004; 34: 340-345.

75 Komatsu N, Takata M, Otsuki N, et al. Elevated stratum corneum hydrolytic activity in Netherton syndrome suggests an inhibitory regulation of desquamation by SPINK5-derived peptides. J Invest Dermatol 2002; 118: 436-443.

76 Whittaker PA. Genes for asthma: much ado about nothing? Curr Opin Pharmacol 2003; 3: 212-219.

77 Van Eerdewegh P, Little RD, Dupuis J, et al. Association of the ADAM33 gene with asthma and bronchial hyperresponsiveness. Nature 2002; 418: 426-430.

78 De Sanctis GT, Merchant M, Beier DR, et al. Quantitative locus analysis of airway hyperresponsiveness in A/J and C57BL/6J mice. Nat Genet 1995; 11: 150-154.

79 Powell RM, Wicks J, Holloway JW, Holgate ST, Donna DE. The splicing and fate of ADAM33 transcripts in primary human airways fibroblasts. Am J Respir Cell Mol Biol 2004; 31: 13-21.

80 Garlisi CG, Zou J, Devito KE, et al. Human ADAM33: protein maturation and localization. Biochem Biophys Res Commun 2003; 301: 35-43.

81 Shapiro SD, Owen CA. ADAM-33 surfaces as an asthma gene. N Engl J Med 2002; 347: 936-938.

82 Howard TD, Postma DS, Jongepier H, et al. Association of a disintegrin and metalloprotease 33 (ADAM33) gene with asthma in ethnically diverse populations. J Allergy Clin Immunol 2003; 112: 717-722.

83 Werner $\mathrm{M}$, Herbon $\mathrm{N}$, Gohlke $\mathrm{H}$, et al. Asthma is associated with single-nucleotide polymorphisms in ADAM33. Clin Exp Allergy 2004; 34: 26-31.

84 Lee JH, Park HS, Park SW, et al. ADAM33 polymorphism: association with bronchial hyper-responsiveness in Korean asthmatics. Clin Exp Allergy 2004; 34: 860-865.

85 Cheng L, Enomoto T, Hirota T, et al. Polymorphisms in ADAM33 are associated with allergic rhinitis due to Japanese cedar pollen. Clin Exp Allergy 2004; 34: 1192-1201.

86 Blakey JD, Halapi E, Bjornsdottir U, et al. The contribution of ADAM33 polymorphisms to the population risk of asthma. Thorax 2005; 60: 274-276.

87 Jongepier H, Boezen HM, Dijkstra A, et al. Polymorphisms of the ADAM 33 gene are associated with decline in $\mathrm{FEV}_{1}$ in a Dutch asthma population. Am J Respir Crit Care Med 2003; 167: A749. 
88 Allen M, Heinzmann A, Noguchi E, et al. Positional cloning of a novel gene influencing asthma from chromosome 2q14. Nat Genet 2003; 35: 258-263.

89 Laitinen T, Polvi A, Rydman P, et al. Characterization of a common susceptibility locus for asthma-related traits. Science 2004; 304: 300-304.

90 Keith T, Little R, Van Eerdewegh P, et al. Genome Therapeutics Corporation. Human genes relating to respiratory disease and obesity. US patent 09/627, 465; 2004.

91 Seong JK, Koo JS, Lee WJ, et al. Upregulation of MUC8 and downregulation of MUC5AC by inflammatory mediators in human nasal polyps and cultured nasal epithelium. Acta Otolaryngol 2002; 122: 401-407.

92 Song KS, Seong JK, Chung KC, et al. Induction of MUC8 gene expression by interleukin- 1 beta is mediated by a sequential ERK MAPK/RSK1/CREB cascade pathway in human airway epithelial cells. J Biol Chem 2003; 278: 34890-34896.

93 Oguma T, Palmer LJ, Birben E, Sonna LA, Asano K, Lilly CM. Role of prostanoid DP receptor variants in susceptibility to asthma. N Engl J Med 2004; 351: 1752-1763.

94 Nicolae D, Cox NJ, Lester LA, et al. Fine mapping and positional candidate studies identify HLA-G as an asthma susceptibility gene on chromosome 6p21. Am J Hum Genet. 2005; 76: 349-357.

95 Rizzo R, Mapp CE, Melchiorri L, et al. Defective production of soluble HLA-G molecules by peripheral blood monocytes in patients with asthma. J Allergy Clin Immunol 2005; 115: 508-513.
96 Colilla S, Nicolae D, Pluzhnikov A, et al. Collaborative Study for the Genetics of Asthma. Evidence for geneenvironment interactions in a linkage study of asthma and smoking exposure. J Allergy Clin Immunol 2003; 111: 840-846.

97 Gao PS, Heller NM, Walker W, et al. Variation in dinucleotide (GT) repeat sequence in the first exon of the STAT6 gene is associated with atopic asthma and differentially regulates the promoter activity in vitro. $J$ Med Genet 2004; 41: 535-539.

98 Koppelman GH. Gene by environment interaction in asthma. Curr Allergy Asthma Rep 2006; 6: 103-111.

99 Gilliland FD, Gauderman WJ, Vora H, Rappaport E, Dubeau L. Effects of glutathione-S-transferase M1, T1, and P1 on childhood lung function growth. Am J Respir Crit Care Med 2002; 166: 710-716.

100 World Health Organization. Health Aspects of Air Pollution. Results from the WHO "Systematic Review of Health Aspects of Air Pollution in Europe", June 2004. www.euro.who.int/document/E83080.pdf. Date last accessed: January, 25: 2007.

101 Vignola AM, Chiappara G, Siena L, et al. Proliferation and activation of bronchial epithelial cells in corticosteroiddependent asthma. J Allergy Clin Immunol 2001; 108: 738-746.

102 Hart LA, Krishnan VL, Adcock IM, Barnes PJ, Chung KF. Activation and localization of transcription factor, nuclear factor-kappaB, in asthma. Am J Respir Crit Care Med 1998; 158: 1585-1592.

103 Davies N, Peakman T, Arlington S. From targets to targeted treatment solutions. Drug Discov Today 2004; 9: 245-247. 